\title{
TELEWORKING IN THE MANAGEMENT OF INTERNATIONAL TEAMS - EXPERIENCE REPORT
}

\author{
Leonilde Reis ${ }^{1}$ \\ Clara Silveira ${ }^{2}$ \\ Renato Duarte ${ }^{3}$
}

Received: November 9, 2020 / Revised: February 19, 2021 / Accepted: April 15, 2021

(C) Association of Economists and Managers of the Balkans, 2021

\begin{abstract}
The use of information and communication technologies in an organizational context allows enhancing performance and defining business support strategies. The objective of this paper is to research the importance of teleworking in order to reflect the conditions for monitoring international project teams, and in this sense to contribute to the optimization of the practices instituted. The most common business processes of organizations are supported by generic software products, also called enterprise resource planning, in which the organization consolidates its experience over time in order to provide increasingly better services. The main contributions of the paper focus on the presentation of the fundamental competences of the teams regarding the performance in configuration projects in view of the practical experience in the international labor market in face of pandemic scenario.
\end{abstract}

Keywords: Project management, Telework, Sustainability, Information and communication technologies, Information systems.

JEL Classification J53 $\cdot$ M15

leonilde.reis@esce.ips.pt

Polytechnic Institute of Setúbal, Portugal, Campus de IPS, Estefanilha, Setúbal, Portugal

Polytechnic Institute of Guarda, Portugal, Avenida Dr. Francisco Sá Carneiro, n. ${ }^{\circ} 50$, Guarda, Portugal

IT Project Manager, Rua Saraiva de Carvalho, $149-4^{\circ}$ Dto, Lisbon, Portugal 


\section{INTRODUCTION}

The use of information and communication technologies as an abutment to the information systems in an organizational context allows enhancing performance and defining business support strategies. The theme of implementing/configuring/customizing enterprise resource planning (ERP) systems (Ahmad \& Cuenca, 2013, Daneva \& Wieringa, 2008, Dittrich, Vaucouleur, \& Giff, 2009, Silva \& Alves, 2001, Silveira, Faria, Aguiar, \& Vidal, 2005) or enterprise system (Davenport, 2000, Haines, 2009) also designated generic software products. An ERP system provides organizations with a comprehensive way to manage their business. It should be flexible in order to accommodate or enhance existing processes, or even propose new approaches to bring added value to the organization. These can be internal processes or processes that interact with other systems.

The transfer of knowledge between teams that implement generic software products, in an international context, is the main motivation. This is a knowledge that is encapsulated and sometimes difficult to transfer. Also the need to include sustainability concerns (Becker, et al., 2015, Reis \& Silveira, 2020, Reis, Silveira, Carvalho, \& Mata, 2020, Reis et al., 2020, Venters et al., 2018) in implementation projects is an increased motivation.

Sustainability is comprehensive and multi-dimensional, in order to include the economic, social, environmental, technical and individual (personal) dimensions to tend to the nature of sustainability in any situation (Becker et al., 2015). The increasing dissemination of the use of information and communication technologies and information systems as support for people management activities can be a competitive advantage and a contribution to the promotion of sustainable development (Reis, Silveira, Carvalho, \& Mata, 2020). Combining technological innovation with the various dimensions of where there is no sustainability becomes increasingly necessary, allowing the environment to be preserved and new market opportunities achieved.

\section{PROBLEM FORMULATION IN THE CONTEXT OF THE PANDEMIC}

The implementation of information systems and technologies in international projects is more and more frequent in the global world in which we live. The management of teams in international projects faces different challenges in relation to national projects. The issue of distance, the language, the culture puts small obstacles in the way.

The way to manage these aspects and others is what the authors want to answer to be successful. Another point, that is no less important, is that the management of these projects is being put under the effect of the pandemic. The challenge is creating trust in the customer with an implementation in telework carried out almost entirely remotely.

\section{METHODOLOGY}

The design science research (DSR) methodology is one of the research methods that has been established (Bianchi \& Sousa, 2015) and has been adopted in the area of IS (Roquete, 2018) to solve organizational problems. Thus, the DSR methodology (Peffers, Tuunanen, Rothenberger, \& Chatterjee, 2007) was selected as the theoretical basis to support the scientific validity of this work.

As it is a research methodology indicated for research projects in technologies and IS, system architectures (Ferreira, Ferreira, Silva, \& Carvalho, 2012), and parameterization/customization activity of generic software products, it ensures discipline, rigor and transparency. 


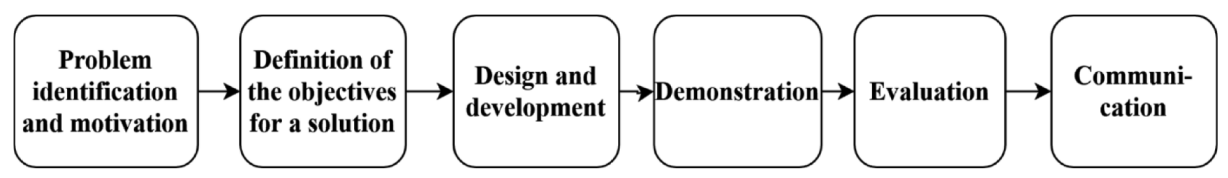

Figure 1. Design science research steps

Source: Adapted from (Peffers, Tuunanen, Rothenberger, \& Chatterjee, 2007)

The scheme of this methodology is shown in Figure 1 (Peffers, Tuunanen, Rothenberger, \& Chatterjee, 2007). The DSR process (Figure 1) includes six steps: problem identification and motivation, the definition of the objectives for a solution, design and development, demonstration, evaluation, and communication. The DSR methodology allows, in this context, to identify the underlying problem in the evaluation of international project teams in order to create an artefact.

\section{TELEWORKING IN THE INTERNATIONAL PROJECT TEAMS}

The term telework or teleworking is an umbrella for the use of information and communication technology to perform work at a distance, as well as after-hours work activity by commuters (Mokhtarian, Collantes, \& Gertz, 2004). Telecommuters, or paid employees who work from home instead of commuting daily, are a subset of teleworkers and are the focus of current attention (Moos, Andrey, \& Johnson, 2006). The social sustainability implications of using information and communication technologies can be difficult to deduce and measure.

On the other hand, the digital transformation is changing many sectors of activity and possibly making the world more sustainable, allowing to preserve the environment, and achieving new opportunities. Therefore, Figure 2, analyses teleworking in the five dimensions of sustainability (Becker, et al., 2015), under different perspectives, such as:

Dimension One: Economic sustainability aims at maintaining capital and added value;

Dimension Two: Social sustainability aims at preserving the societal communities in their solidarity and services;

Dimension Three: Technical sustainability refers to longevity of information, systems, and infrastructure and their adequate evolution with changing surrounding conditions;

Dimension Four: Individual sustainability refers to maintaining human capital (e.g., health, education, skills, knowledge, leadership, and access to services);

Dimension Five: Environmental sustainability refers to improving human welfare by protecting the natural resources: water, land, air, minerals and ecosystem services.

These dimensions are interrelated and provide an instrument to disaggregate and analyse relevant issues, taking into account that sustainability is fundamental to our society. The central factors of telework are represented in individual, social and environmental sustainability. The role of technologies is illustrated in the technical dimension.

Analyzing Figure 2, the economic dimension shows an advantage that many organizations see with telecommuting that is lowered overhead costs and reduced office space (Duarte, Reis, \& Silveira, 2020). This can be a significant advantage to an organization looking to reduce expenses.

The appearance of the pandemic has brought drastic changes in project management. In projects taking place in face-to-face, the teams had to return to their country of origin leaving the client's premises where the project was being implemented. This situation arose practically from one 
moment to the next without warning, and of course it is due to governmental impositions, leaving people confused. In particular, customers felt the change in the project implementation from one moment to the next, without knowing how the project would proceed. In projects that were about to start, given the impossibility of traveling and carrying out a face-to-face implementation (as planned), the big challenge was to convince customers that the project could be started remotely in telework. In the two previous situations, creating trust in the customer was the first challenge that a project implementation in teleworking is possible.

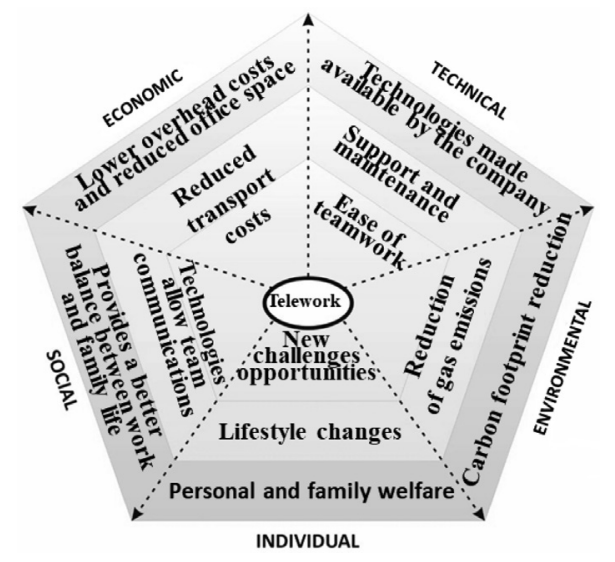

Figure 2. Sustainability dimensions - teleworking in the international projects Source: Duarte, Reis, \& Silveira, 2020

Another challenge, not less important, is the management of working hours. In projects in Europe, the time difference can be compatible, and it is possible to reconcile the working hours between the customer and the ERP provider for a normal 8-hour working day. However, in projects in Asia the time difference is no longer compatible, a time of 4 to 5 hours' maximum can be reconciled, not more. This issue causes the direct work with the customer to be drastically reduced by half. One of the obvious consequences is that the duration of the project, which was foreseen for a face-to-face implementation, will have a longer duration for the adoption of remote work, the only possible way to continue the project.

\section{EXPERIENCE DESCRIPTION}

Describing experiences is a resource for those who want perspectives on what others do and the lessons they have learned along the way. In this sense, it is intended to promote knowledge and the sharing of experiences that occurred during the pandemic in the implementation of ERP in an international context. The scope of the experience report presented here is always directed towards international projects. In this case, these are projects run by a Portuguese company in countries other than Portugal.

With the aim of carrying out the implementation of a project for a generic ERP system, a set of good practices were adopted in order to enhance the results. These good practices can be divided into three categories that are considered to be the main ones and exemplified in Figure 3: Team; documentation and implementation. 


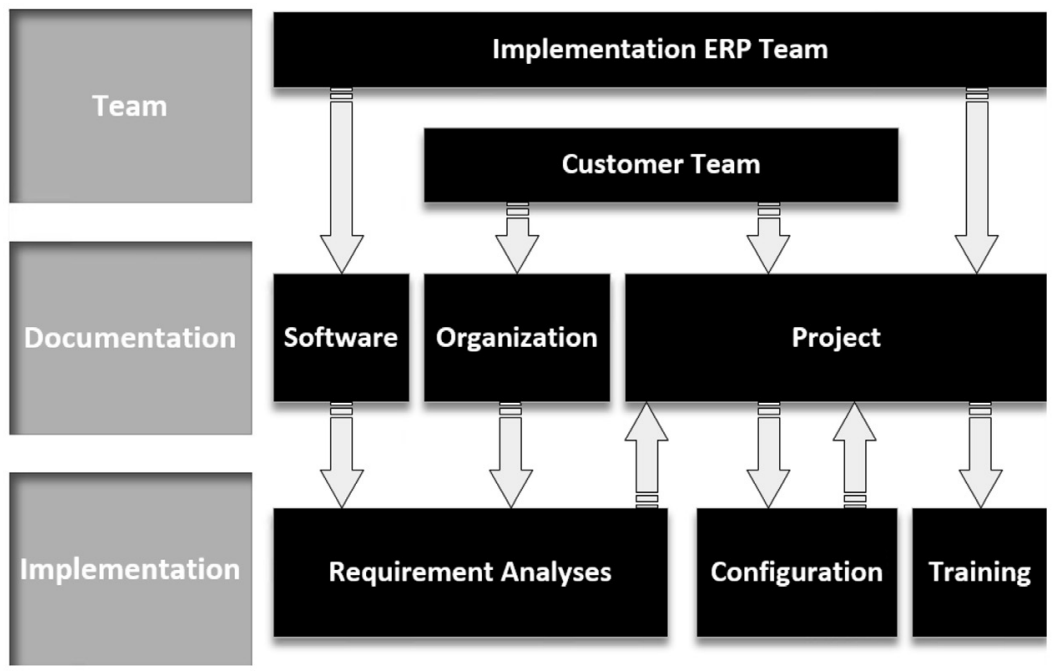

Figure 3. Organization/basic workflow in the international projects Source: Authors

In terms of setting up an ERP Implementation Team in international projects in the context of the pandemic, the following was considered.

Point 1: Be multidisciplinary with necessary knowledge within the scope of the project;

Point 2: English language skills;

Point 3: Involve a local partner (when possible).

The local partner, for its part, should: have English language skills (in addition to the native language of the country where the project is being implemented), have knowledge of cultural and organizational reality and have knowledge of the legal aspects in force (commercial, stocks, accounting, ...); having defined the role to be played: interlocutor between the ERP implementation team and the customer team.

Regarding the constitution of the customer team, the following good practices are proposed:

Issue 1: Have knowledge of the English language (sometimes the pronunciation makes communication difficult);

Issue 2: Existing processes skills (sometimes knowledge is superficial on the part of key users);

Issue 3: Prepared for change (sometimes only key users are aware of this);

Issue 4: Be available, practically in full, for the period of implementation of the project. Sometimes, since the organization does not cease activity, availability is affected which causes cancellation of meetings and project delay. In the perspective of (Ahmad \& Cuenca, 2013) the implementation processes must be carried out without affecting daily operations throughout the company. This can only be achieved with an understanding of the main elements that make up the organization's infrastructure, an effective plan for implementation and procedures for measuring and evaluating the project throughout the implementation process.

In terms of the documentation provided by the ERP implementation team, it is necessary:

Issue 1: Provide documentation for installation/configuration of server and client stations;

Issue 2: Provide process diagrams (sometimes there are several scenarios); 
Issue 3: Have general configuration templates;

Issue 4: Provide documentation as Mini User Guides: they are the substitutes for the HowTo documents and FAQs;

Issue 5: A daily record of the work carried out, explaining the main decisions taken, always with the customer's agreement;

Issue 6: Use of integrated project management software in order to record and document all interactions carried out, in order to allow the entire team to have access to all project information in an integrated and dynamic way;

Issue 7: Provide the so-called User Manual (preferably online).

In terms of the documentation provided by the customer team, it is necessary:

Issue 1: Be in English (preferably);

Issue 2: Prepare and provide the information about processes/workflows, including used internal and external documents (sometimes this information is only prepared when requested and takes a long time).

Regarding the implementation of the project we can divide it into the following points:

Point 1: Requirement Analyses;

Point 2: Configuration;

Point 3: Training.

The requirement analyses must consider the following aspects:

Aspect 1: Must be with project managers, key users (and end users when necessary);

Aspect 2: The customer team can present their own processes or the ERP implementation team can present the processes support by the ERP (this depends on the project to be carried out);

Aspect 3: All decisions taken must be documented.

The configuration involves the following aspects:

Aspect 1: Be with the project manager (and key users when necessary);

Aspect 2: Use a general template;

Aspect 3: Use the requirement analyses documentation as a process guide;

Aspect 4: Make presentations to key users for each configured process.

The training must address the following aspects:

Aspect 1: It has to be done with the project manager, with key users and end users (sometimes it is a long process due to the necessary translations from English into native language);

Aspect 2: Carried out, as a complement, at the end user's workstation;

Aspect 3: Provide the respective Mini User Guide document to the end user;

Aspect 4: Given a period of time to user to carry out their tests.

It is recommended that the configuration/training finishes only when the following aspects are verified by the end user at his workplace: the ERP System must be tested/used; printing of documents; sending emails; import/export data; interaction with other specific devices. One of the great challenges that was faced in operational terms in the management of teams in international teleworking projects, was project planning. 


\section{CONCLUSION}

In international projects the management of teams in teleworking faces several challenges that have to be managed carefully. The main question to be successful with this new reality is to carry out an even more careful planning, considering these new factors that are imposed by the pandemic. The time spent on more careful planning will be compensated, in time, by the operational side.

The planning of the project has to be more rigorous, the operational part has to be carried out in a smoother way, which implies more project time. Scheduled meetings must be strictly adhered to, postponements should be avoided as much as possible. The availability of the teams for a new way of working has to be total.

If there is a local partner, who already has worked in the implementation of previous projects, it can prove to be a fundamental asset. His work in helping the customer, preparing for meetings, additional clarifications, training and support will give a significant boost to the project. With a local partner problems issues are minimized.

\section{REFERENCES}

Ahmad, M., \& Cuenca, R. (2013). Critical success factors for ERP implement. Robotics and Computer-Integrated Manufacturing, 29, 104-111.

Becker, C., Chitchyan, R., Duboc, L., Easterbrook, S., Penzenstadler, B., Seyff, N., \& Venters, C. (2015). Sustainability Design and Software: The Karlskrona Manifesto. Proc. 37th International Conference on Software Engineering (ICSE 15).

Bianchi, I., \& Sousa, D. (2015). Governança de TI em universidades públicas: Proposta de um modelo. Retrieved from CAPSI'2015: http://hdl.handle.net/1822/39467

Daneva, M., \& Wieringa, R. (2008). Cost estimation for cross-organizational ERP projects: research perspectives. (S. Netherlands, Ed.) Software Quality Journal, Vol. 16, Nº 3, 459-481.

Davenport, T. (2000). Mission critical: realizing the promise of enterprise systems. Harvard Business School Press: Boston.

Dittrich, Y., Vaucouleur, S., \& Giff, S. (2009). ERP customization as software engineering: knowledge sharing and cooperation. IEEE Software, 26, 41-47.

Ferreira, I., Ferreira, S., Silva, C., \& Carvalho, J. (2012). Dilemas iniciais na investigação em TSI design science e design research, uma clarificação de conceitos. Conferência Ibérica de Sistemas y Tecnologias de Informação.

Haines, M. (2009). Understanding Enterprise System Customization: An Exploration of Implementation Realities and the Key Influence Factors. Information Systems Management, 26:2, 182-198.

Mokhtarian, P., Collantes, G., \& Gertz, C. (2004). Telecommuting, residential location, and commute-distance traveled: evidence from state of California employees. Environment and Planning A, 36(10):1877-1897.

Moos, M., Andrey, J., \& Johnson, L. (2006). The sustainability of telework: an ecological-footprinting approach. Sustainability: Science, Practice and Policy, 2:1,3-14.

Peffers, K., Tuunanen, T., Rothenberger, M., \& Chatterjee, S. (2007). A Design Science Research Methodology for Information Systems Research. Journal of Management Information Systems, Volume 24 Issue 3, Winter 2007-8, 45-78.

Reis, L., \& Silveira, C. (2020). Sustentabilidade Multidimensional em Sistemas de Informação. XXX Jornadas Luso-Espanholas de Gestão Cientifica. Instituto Politécnico de Bragança. 
Reis, L., Silveira, C. \& Duarte, R. (2020). Sustainability Factors in International Project Teams. 6th International Scientific Conference on Knowledge Based Sustainable DevelopmentERAZ 2020, pp. 271-278. DOI: https://doi.org/10.31410/ERAZ.2020.271

Reis, L., Silveira, C., Carvalho, L., \& Mata, C. (2020). Digitalization as a key issue of the Circular Economy to promote Sustainability: Prototyping Design for Homeless People. In P. A. S. Rodrigues (Ed.), Mapping, Managing, and Crafting Sustainable Business Strategies for the Circular Economy. USA: IGI Global.

Roquete, M. (2018). Modelo de maturidade para apoio à implementação de uma filosofia de gestão orientada a processos numa organização. Nova Information Management School.

Silva, F., \& Alves, J. (2001). ERP e CRM: da empresa à e-empresa - soluções de informação reais para empresas globais. Lisboa: Edições Centro Atlântico.

Silveira, C., \& Reis, L. (2021). Sustainability in Information and Communication Technologies. In Carvalho, L. C., Reis, L., Prata, A., \& Pereira, R. (Ed.), Handbook of Research on Multidisciplinary Approaches to Entrepreneurship, Innovation, and ICTs (pp. 375-396). IGI Global. http://doi:10.4018/978-1-7998-4099-2.ch017.

Silveira, C., Faria, J., Aguiar, A., \& Vidal, R. (2005). Wiki Based Requirements Documentation of Generic Software Products. The Tenth Australian Workshop on Requirements Engineering, Editors: K. Cox, J. L. Cybulski, L. Nguyen, J. W. Lamp, R. Melbourne, Austrália.

Venters, C. C., Capilla, R., Betz, S., Penzenstadler, B., Crick, T., Crouch, S., \& Elisa Yumi Nakagawa, C. B. (2018). Software sustainability: Research and practice from a software architecture viewpoint. Journal of Systems and Software, 138, 174-188. 